\title{
Wild Cultures: A Comparison between Chimpanzee and Human Cultures
}

Christophe Boesch. 2012. Cambridge University Press. Pp. 276, 68 b \& w illustrations, 11 tables. $f 60$ (hardback). ISBN 9781109025370.

\section{Reviewed by Diana Rocío Carvajal Contreras}

Reviewer address: Facultad de Estudios de Patrimonio Cultural, Carrera de Arqueología, Universidad Externado de Colombia. diana.carvajal@uexternado.edu.co

In Wild Cultures: A Comparison between Chimpanzee and Human Cultures Christophe Boesch, professor and director of the department of primatology at Max Planck Institute of Evolutionary Anthropology in Germany, employees a comparative ethnographic approach to discuss the controversial topic of animal culture in apes and its diversity in comparison to human culture.

Through the nine chapters of this book and based on his long research experience in Côte d'Ivoire and Gabon, Boesch makes compelling contributions to the ongoing debate about human and animal culture. Although the book is written for professional experimental psychologists, it will also be of interest to students in psychology, anthropology, primatology, and biology, as well as professional social and biological scientists. Indeed, the author's style makes thorny issues more accessible to a general audience such as our uniqueness as human beings, the nature of our close chimpanzee relatives, and the definition of culture.

In my view, this book provides both a methodological twist and a new point of departure for thinking about the theoretical opposition between the notions of human/animal and culture/nature among Western scholars. In proposing a holistic perspective, Boesch questions the closed groups in which we have enclosed ourselves as social scientists and biologists in regard to discussions about what makes us human, what we share with other primates, and how we obtained our unique characteristics (Morin 1973). He also points out that the question of "what makes us humans" entails such complexity in the definition of culture in nature that it can only be answered by admitting that both humans and animals have culture.
In the first two chapters, Boesch reviews approaches to the study of animal culture and definitions of culture. He goes on to suggest that our greatest limitation in understanding culture, as well as observing and describing similarities and differences between Homo sapiens and other primate species, is our tendency for ethnocentric and anthropocentric thinking. In other words, we admit our close evolutionary heritage but do not think of ourselves as primates. We consider ourselves far from nature, and we have a "superior" position due to culture (García Raso 2013; Haslam et al. 2009). In order to make valid comparisons, Boesch argues that cultural phenomena are the result of interactions between ecological conditions and actions of group members. Therefore, culture in humans and chimpanzees is reflected in material, symbolic, and social domains. He criticizes the research and validity of experimental studies on cognition without a social context - "culture outside of culture" - because cultural behaviors are best observed in natural habitats during normal social interactions. He explains that through an ethnographic field approach it is possible to witness, observe, experience, and describe these behavioral processes among chimpanzees. This approach has the potential to further enrich our understanding of chimpanzee cultural diversity and facilitates comparison with human culture.

In the third chapter, Boesch describes the material culture domain among chimpanzees by comparing different populations. He demonstrates how the creation and use of tools broadens access to new food sources and shapes their physical world, which in the end plays a crucial role in the survival of individuals. He suggests that successive generations may socially 
learn and improve techniques that build on earlier achievements through a cumulative evolutionary process. This is similar to human material cultures even though humans face a greater diversity of environments and therefore have a greater diversity of tools.

In the next chapter, Boesch discusses the importance of social culture for chimpanzees. Their social culture expresses itself in various social behaviors long assumed to be unique to Homo sapiens, such as hunting cooperation, altruism, and sharing food. The differences in social behaviors among chimpanzee populations are related to ecological differences and are decisive to the survival of individuals of each group.

In chapter five, Boesch reveals that different populations of chimpanzees-Taï, Mahale, and Bossu-invent symbols and adhere to cultural conventions. Using selected examples, Boesch argues that none of these are uniquely human characteristics. According to Boesch, basic aspects of this symbolic domain are shared by humans and chimpanzees.

After reviewing chimpanzee achievements in the three cultural domains (material, social, and symbolic), Boesch focuses on how chimpanzees teach and acquire cultural traits. He emphasizes the importance of imitating behavior for juvenile individuals, not only from their mothers but from other members of the group as well, and how vital such learning is for their survival as adult group members. According to the author, this pattern is similar to how humans acquire culture, but the parallels include the diversity of teaching styles. The teaching style is in accordance with the task in either material or symbolic domains and varies according to the particular population.

Chapter seven addresses how chimpanzees react to death and injuries of group members. Boesch presents compelling evidence that Ivorian and Tanzanian chimpanzees, like elephants, dolphins, whales, gorillas, and humans, share an understanding of the notion of death and strong empathy toward individuals in need.

In the next chapter, Boesch compares chimpanzee and human culture and cognition. However, due to the scarcity of studies in other chimpanzee communities and the destruction of their habitats, data are insufficient to make meaningful comparisons. Boesch suggests that such comparisons require future research. The author also questions whether the divergence between findings from captive and wild chimpanzees may be related to the social and natural environments. In other words, chimpanzees in captivity are not representatives of all species. As in humans, the conditions in which they develop have important effects on their cognitive development.

In the last chapter, the author reviews the themes of the book with an emphasis on the uniqueness of human and chimpanzee cultures, rather than on their similarities. He argues that human uniqueness is related to the diversity in material culture, a mixture of learning mechanisms, complex social culture, and a greater degree of symbolic culture. The author adds that uniqueness is even more marked by the language skills of our species and the different environmental challenges that humans faced during their evolution. In comparison, chimpanzee culture has the same three cultural domains but to a lesser degree. Chimpanzees use learning mechanisms such as teaching and imitation.

I found Boesch's arguments appealing for his intended audience. His use of tables, diagrams, and pictures encourages reflection about the separation between chimpanzees and humans, the dichotomy between nature and culture, and the perceptions of the social and biological sciences with regard to the status of chimpanzees (Strier 2003). The initial comparison proposed by Boesch is a meaningful contribution to our understanding of human evolution and distinctiveness and towards a redefinition of our dualistic point of view about human-animal boundaries. The numerous examples presented in this book are clear indications that primatology from the methodological point of view is not going back and forth from ethnography to ethology. Both perceptions and methodologies will work in an integrative way to understand behavioral variation between humans and chimpanzees.

\section{References Cited}

García Raso, D. 2013. Los Otros Hijos de Efesto: Uso y

Fabricación de Herramientas en Animales no Humanos.

JAS Arqueología, Madrid.

Haslam, M., A. Hernandez-Aguilar, V. Ling, S. Carvalho, I. de la Torre, A. DeStefano, A. Du, B. Hardy, J. Harris, L. Marchant, T. Matsuzawa, W. McGrew, J. Mercader, R. Mora, M. Petraglia, H.

Roche, E. Visalberghi, and R. Warren. 2009. Primate Archaeology. Nature 460:339-344.

Morin, E. 1973. El Paradigma Perdido, Ensayo de 
Bioantropología. Editorial Kairos, Barcelona.

Strier, K. 2003. Primate Behavioral Ecology: From

Ethnography to Ethology and Back. American

Anthropologist 105:16-27. 